Original research article

\title{
The effect of differential training-based occupational therapy on hand and arm function in patients after stroke: Results of the pilot study
}

\author{
Viktorija Repšaite $\dot{e}^{a, *}$, Alfonsas Vainoras ${ }^{a}$, Kristina Berškiené ${ }^{a}$, \\ Daiva Baltaduoniene $\dot{e}^{b}$, Algé Daunoravičien $\dot{e}^{a}$, Ernesta Sendžikaite ${ }^{a}$ \\ ${ }^{a}$ Institute of Sports, Faculty of Nursing, Lithuanian University of Health Sciences, Kaunas, Lithuania \\ ${ }^{\mathrm{b}}$ Department of Rehabilitation, Faculty of Nursing, Lithuanian University of Health Sciences, Kaunas, Lithuania
}

\section{A R T I C L E I N F O}

\section{Article history:}

Received 22 January 2015

Received in revised form

15 March 2015

Accepted 11 April 2015

Available online 24 April 2015

Keywords:

Stroke

Cerebral infarction

Occupational therapy

Arm function

Differential training

\begin{abstract}
A B S T R A C T
Objective: The aim of this study was to evaluate the effect of differential training-based occupational therapy on the recovery of arm function and to compare these data with the results obtained after conventional occupational therapy.

Methods: A total of 27 patients who had suffered a cerebral infarction in the left brain hemisphere were recruited for the study. There were 9 men (33.33\%) and 18 women (66.67\%). All the patients had paresis of the right arm. The patients were divided into 2 groups: the control group comprised 15 patients who were given conventional occupational therapy ( 5 times per week) and the study group consisted of 12 patients who underwent conventional occupational therapy ( 3 times per week) along with occupational therapy based on differential training (2 times per week).

Results: In the control group, the mean performance time of only 2 tasks, i.e., flip cards and fold towel, improved significantly $(P<0.05)$, while significant deterioration in the mean performance time of the task "lift can" was observed $(P<0.05)$. In the study group, the mean performance time of all the tasks except for forearm to box (side), hand to box (front), and lift paperclip improved significantly $(P<0.05)$, and no deterioration in arm function was observed.

Conclusion: Both patients' groups improved arm function after occupational therapy sessions, but the patients who underwent conventional occupational therapy along with differential training-based occupational therapy recovered their arm function more effectively than their counterparts after conventional occupational therapy.
\end{abstract}

(C) 2015 Polish Neurological Society. Published by Elsevier Sp. z o.o. All rights reserved.

\footnotetext{
* Corresponding author at: Institute of Sports, Faculty of Nursing, Lithuanian University of Health Sciences, Kalniečių 231, Kaunas LT-50108, Lithuania. Tel.: +370 62014635 .

E-mail addresses: viktorija.repsaite@gmail.com (V. Repšaitè), alfavain@gmail.com (A. Vainoras), k.berskiene@gmail.com (K. Berškienè), daibalt@gmail.com (D. Baltaduonienè), algevita@gmail.com (A. Daunoravičienè), ernestasendzik@gmail.com (E. Sendžikaitè). http://dx.doi.org/10.1016/j.pjnns.2015.04.001 0028-3843/C 2015 Polish Neurological Society. Published by Elsevier Sp. z o.o. All rights reserved.
} 


\section{Introduction}

Cerebral infarction is an acute focal cerebral circulatory disorder characterized by focal neurological symptoms persisting longer than $24 \mathrm{~h}$ from the onset of the disease. Cerebral infarction accounts for $80-85 \%$ of all strokes. Its incidence varies in different countries and ranges from 100 to 300 cases per 100000 population annually. During the last decades, no changes in stroke morbidity rates have been reported in many Western European countries, but some countries have evidenced a marginal increase. In Lithuania, the stroke morbidity rate is high as compared with other countries [1], and approximately 4-5 people per 10000 are affected by stroke every year. Risk factors for stroke include genetic predisposition to vascular diseases, brain and cardiovascular diseases, hyperlipidemia, hyperglycemia, obesity, hypertension, hypodynamics, smoking, and stress. If there are more than two risk factors, the probability of getting a stroke is higher. In Lithuania, this disease poses not only a medical but also social burden because only about $20 \%$ of the stroke survivors become able-bodied again after stroke [1,2]. In Lithuania, about $80 \%$ of the patients with stroke become disabled due to impaired cognitive and motor functions disconcerting their daily operations and efficiency [2].

Arm function is one of the most important functions of the human daily environment, and it a very important component of quality of life. Up to $85 \%$ of all the persons with stroke have an impaired arm [3,4]. Arm dysfunction is one of the biggest problems in patients with a residual cerebral infarction. Arm dysfunction leads to movement limitations and sensory disorders, and a person cannot independently perform a variety of daily tasks. Therefore, the rehabilitation of the affected arm remains a challenge and aims at fast and highquality recovery of the arm function $[3,4]$.

Occupational therapy is one of the rehabilitation methods focused on the repetition of exercises. It aims at improving and restoring patient's physical, mental, and social skills in activities of daily living, work, and leisure. From the very beginning of the disease, all efforts should be put in order to facilitate independent living of the patient $[5,6]$.

Differential training as an alternative to repeated movements is a method gaining more popularity in rehabilitation. Differential training is developed on based on the exploration of neurophysiological and dynamic systems [7]. It activates volatility of human locomotor behavior in order to promote the learner's self-organization. This is the way the learner discovers the individual movements and ways of learning them. Therefore, volatility should not be suppressed but enhanced so that the patient could find individual spaces of possible solutions. To achieve this goal, during the learning phase the patient is faced with a variety of exercises, expanding the boundaries of possible solutions of the assignment. Differential training includes the movement of participating joints, motion geometry, speed, acceleration, time and rhythm, variations of the "classic" motion errors, variations of equipment and environment and combinations of all the options with no repetitions of motion [7]. In other words, a certain skill has to be trained in many different ways, to find the individual and the most optimal way for a particular learner. Since during the differential workout exercises are not repeated, more adequate adaptation to changing conditions is reached [7-9].

Up to now, the effect of differential training on the recovery of arm function during rehabilitation has not been investigated yet. Therefore, based on Schöllhorn's recommendations, who is one of the pioneers of differential training, and benefit of this method in sports, we decided to carry out a study involving patients with a cerebral infarction and to evaluate changes in arm function while applying conventional occupational therapy and occupational therapy based on differential training.

\section{Materials and methods}

\subsection{Study design}

The study was designed as a randomized trial with singleblinded outcome assessment. Before the study, patients who had suffered a cerebral infarction in the left brain hemisphere and who had occupational therapy courses, were randomly divided into two groups: the control group comprised 15 patients (55.56\%), and the study group, 12 patients (44.44\%), according to Mini-mental state examination (MMSE) and Barthel ADL index. To be included into trial, patients had to meet from 50 through 65 points of Barthel index and $\geq 11$ points MMSE criteria. The exlusion criteria were $<50$ and $\geq 70$ points of Barthel index, MMSE $\leq 10$ points, and patients, who have motoric, sensoric or sensomotoric aphasia. These criteria were chosen according to the law of the Ministry of Health of the Republic of Lithuania "Due to the Organization of Medical Rehabilitation and Treatment in the Sanatorium" (No. V-50, January 17, 2008), patients are treated in the Department of Physical Medicine and Rehabilitation for 32 days when they show the Barthel index of 50-65 points and the results of the Mini Mental test (MMT) of 11-30 points.

The therapy was applied to patients when they were transferred from the Neurology Unit to the 2nd Physical Medicine and Rehabilitation Department after 10-14 days from the stroke onset. The control group patients were given a standardized program tailored to individual conventional occupational therapy based on the repetition of exercises (5 times per week). This program included exercises and tools for strengthening upper limb muscles, training the range of motion, and improving fine motor skills and movement coordination. The study group patients underwent occupational therapy based on differential training (2 times/week) along with standardized conventional occupational therapy (3 times/week). This program involved the modified tools of occupational therapy (different size, color, and textures), but the exercises were performed by changing the conditions of performance every time, without repeating the situations and circumstances of the action (exercise) performance.

All the subjects had occupational therapy sessions 5 times a week. The duration of the session was $30 \mathrm{~min}$, and rehabilitation lasted for 32 days. In addition, during rehabilitation, the patients were given the same physical therapy, physiotherapy procedures, and social worker's and psychologist's counseling. 
Table 1 - Material and methods.

\begin{tabular}{llc} 
& $\begin{array}{l}\text { The control } \\
\text { group }\end{array}$ & $\begin{array}{l}\text { The study } \\
\text { group }\end{array}$ \\
\hline $\begin{array}{l}\text { Study population } \\
\text { A total of patients }(n)\end{array}$ & \multicolumn{2}{c}{27} \\
Patients $(n)$ & $15(55.56 \%)$ & $12(44.44 \%)$ \\
Male $(n)$ & $5(33.33 \%)$ & $4(33.33 \%)$ \\
Female $(n)$ & $10(66.67 \%)$ & $8(66.67 \%)$ \\
Age (mean \pm SD) & \multicolumn{2}{c}{$73.93 \pm 7.72$} \\
Age of male (mean \pm SD) & $72.80 \pm 2.82$ & $70.25 \pm 6.79$ \\
Age of female (mean \pm SD) & $77.70 \pm 2.09$ & $71.75 \pm 1.91$ \\
\hline$n$, number of patients. & \multicolumn{3}{c}{} \\
\hline
\end{tabular}

\subsection{Study population}

A total of 27 patients were recruited to the study: 9 men (33.33\%) and 18 women (66.67\%) who had suffered a cerebral infarction in the left brain hemisphere and were hospitalized in the 2nd Physical Medicine and Rehabilitation Department of Kaunas Clinical Hospital, Lithuania, from September 3, 2013, to May 23, 2014. The mean age of the patients was 73.93 years (SD, 7.72; range, 50-88) with men and women being aged 71.67 years $(\mathrm{SD}, 3.18)$ and $75.06(\mathrm{SD}, 1.57)$ on average. All the patients had paresis of the right arm (Table 1).

\subsection{Measures}

Patients' arm function was assessed with the Wolf motor function test, which includes 15 functional tasks. The tasks had to be completed within 120 s. If the patient failed to perform the task within the given time, he/she was considered as not capable of performing it [10].

\subsection{Statistical analysis}

The nonparametric Mann-Whitney test was used for comparisons of two independent samples. To compare two dependent samples, the nonparametric Wilcoxon test was applied. The results are presented as mean (standard deviation). The difference was considered statistically significant at $P<0.05$.

\section{Results}

In the control patients' group, the following tasks were most difficult to perform before occupational therapy: fold towel (16.54 s), flip cards (14.17 s), lift paper clip (13.02 s), and stack checkers (11.79 s) (Fig. 1). The mean performance time of other tasks ranged from $5.35 \mathrm{~s}$ to $1.28 \mathrm{~s}$. After occupational therapy, there was deterioration in arm function while performing the tasks such lift basket in standing position (3.61 s), and lift can $(3.07 \mathrm{~s})$, but only the latter deterioration was statistically significant $(P<0.05)$. Improvement in the mean performance time of all the other tasks was documented, but it was statistically significant only for 2 tasks: flip cards and fold towel $(P<0.05)$ (Fig. 1).

In the study patients' group, the following tasks were most difficult to perform before differential training-based occupational therapy: flip cards $(12.06 \mathrm{~s})$ and fold towel $(11.26 \mathrm{~s})$ (Fig. 2). The mean performance time of other tasks ranged from $5.32 \mathrm{~s}$ to $0.93 \mathrm{~s}$. The patients in the study group showed a

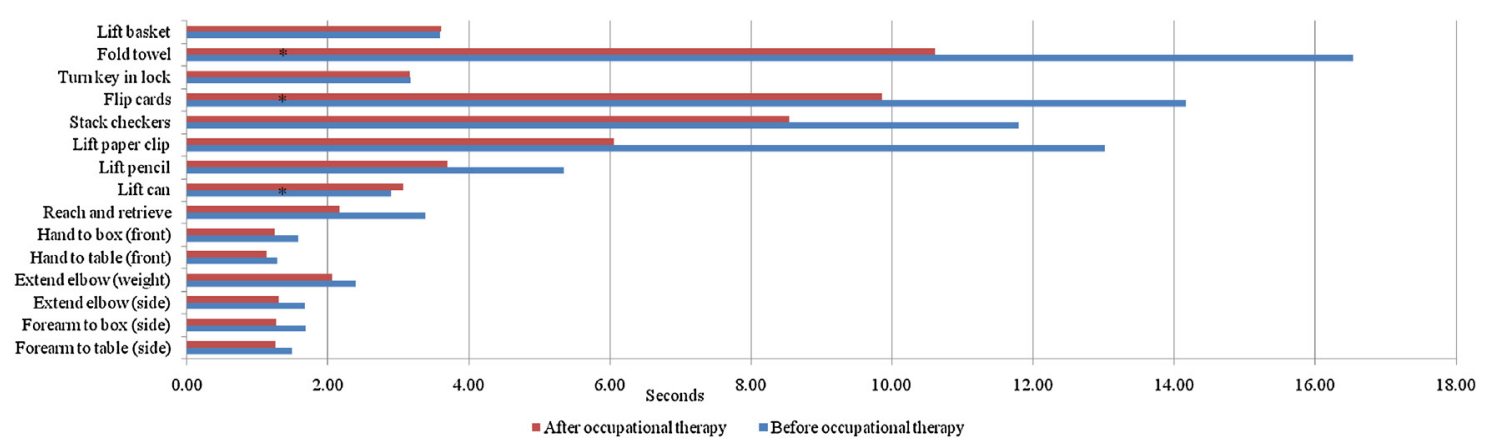

Fig. 1 - Results of the Wolf motor function test in the control group. ${ }^{*} \mathrm{P}<0.05$ before vs. after occupational therapy.

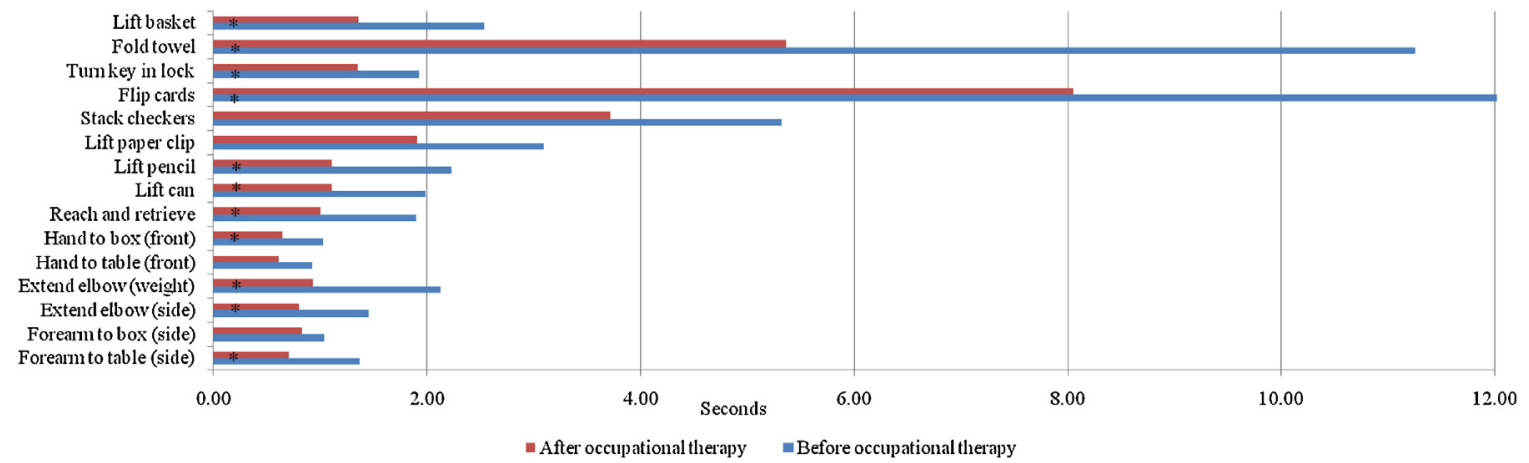

Fig. 2 - Results of the Wolf motor function test in the study group. ${ }^{*} \mathrm{P}<0.05$ before vs. after occupational therapy. 


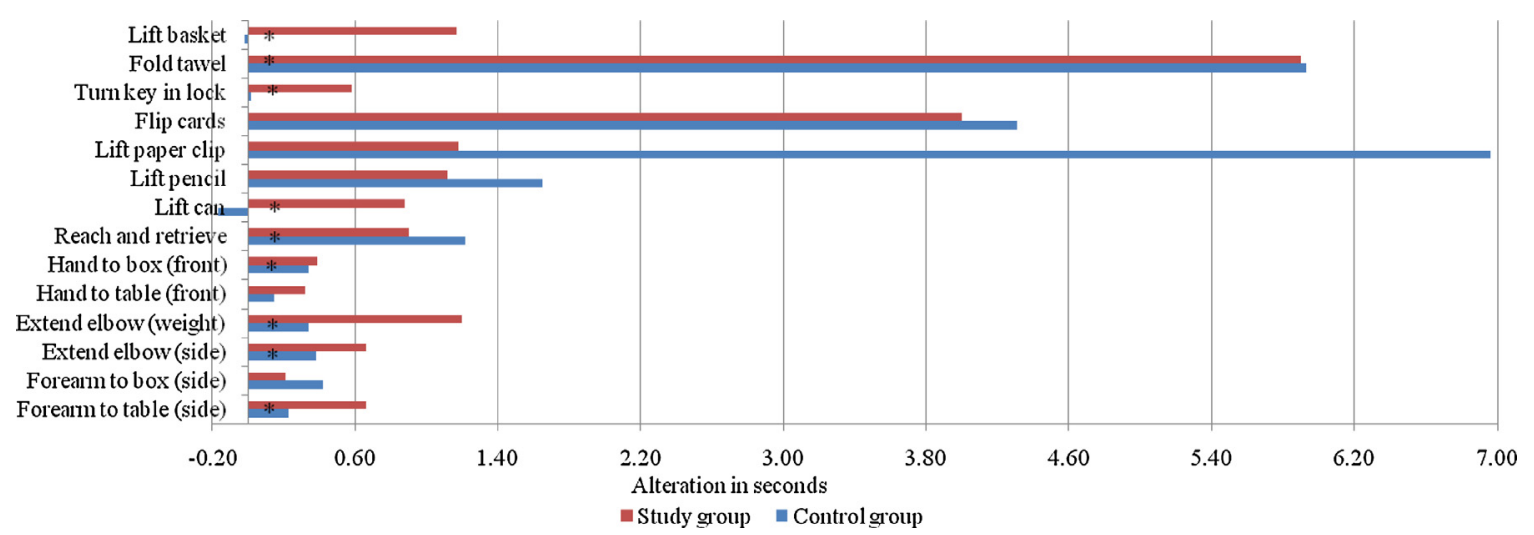

Fig. 3 - Wolf motor activity test results change between the control and study groups. ${ }^{*} \mathrm{P}<0.05$ control group vs. study group.

significant improvement of arm function $(P<0.05)$ in all the tasks except forearm to box (side), hand to table (front), lift paper clip, and stack checkers (Fig. 2).

Fig. 3 depicts the comparison of differences in the performance time of all the tasks before and after occupational therapy between the control and study groups. The differences varied from $-0.17 \mathrm{~s}$ to $6.96 \mathrm{~s}$ and from $0.21 \mathrm{~s}$ to $5.90 \mathrm{~s}$ in the control and study groups, respectively. The comparison revealed statistically significant differences $(P<0.05)$ in a performance time change between the control and study groups for all the tasks except flip cards, lift paperclip, lift pencil, hand to table (front), extend elbow side, and forearm to box.

\section{Discussion}

This study demonstrated that the patients of both groups, who had suffered a cerebral infarction in the left brain hemisphere, experienced improvement in the right arm function after conventional occupational therapy (control group) and occupational therapy based on differential training along with the conventional one (study group), but the performance time was significantly better for more tasks in the study group than the control group. The patients who were given only conventional occupational therapy had a significant improvement in arm function while performing two tasks of the Wolf motor function test, i.e., flip cards and fold towel, and arm function deteriorated significantly while performing the task "lift can". We think that our findings could be related the fact that in the group that was given conventional occupational therapy, the number of repetitions of the same tasks was high, and patients were proactive during the performance of those tasks, i.e., they executed the tasks given by occupational therapists during which CNS automatism took place, and therefore, there were no conditions for the brain to newly activate different brain zones [11-14]. Carr and Shepherd [15] have proposed that high brain activity remains while performing three first repetitions of the task, because later the execution system of brain automatism "turns on".

In the study group after occupational therapy based on differential training along with standardized conventional occupational therapy, the performance time of almost all tasks except for forearm to box (side), hand to table (front), lift paperclip, and stack checkers improved significantly. Although the difference in the performance time of the abovementioned tasks was statistically insignificant, a decreasing trend toward a shorter mean performance time of these tasks after occupational therapy was observed. These results can be explained by the act that task for forearm to box (side) requires pulling away the upper arm, and patients who had suffered a cerebral infarction usually exhibit smaller movement amplitude of the upper extremity, and this task to complete appears to be too complicated. No statistically significant improvement in the task "hand to table (front)" could be explained can be explained by the fact that in the presence of paresis of the arm, the capability to volitionally activate motor units is decreased. Poor or nonvolitional movement of motor units means that muscles and groups of muscles cannot be activated in a timely, coordinated manner nor activated with sufficient force [16]. Failure to significantly improve the performance time of tasks "lift paperclip" and "stack checkers" can be associated with impairments in small movements being most affected after a cerebral infarction $[17,18]$, and therefore, patients find these tacks being too difficult to complete.

The findings of our study are impossible to compare with those of other studies, as to our knowledge, no studies exploring the impact of differential training-based occupational therapy during rehabilitation on arm function have been carried out. Therefore, the discussion is limited to the review and analysis of studies on sports where the differential training approach is widely applied and its positive effect is observed.

Different literature sources suggest that the most common and oldest theoretical approach to learn specific movements is the repetitive approach in which a target movement is repeated frequently for the purposes of imitation. This approach proposes that learners improve a skill just by repeating it. In psychological learning theories, this approach is most similar to learning by imitation in connection with reinforcement learning [8]. Newell et al. demonstrated that in practice the imitations by individuals tend to display decreasing deviations from a to-be-learned movement that can be described by an exponential function [19]. Schöllhorn et al. 
reported that the improvement of a movement implies a deviation from a previous movement execution and, although the learning effect is assigned to the repetition of the execution, it can be questioned whether the learning effect was due to the deviation as well. From this theoretical perspective, therapeutic rehabilitation programs are based on the production of numerous repetitions of a perceived "optimal" exercise pattern by a patient, accompanied by corrective instructions and feedback from therapists [8].

Feys et al. proposed that in patients with arm hemiparesis (after stroke), the recovery of arm function through conventional occupational therapy can improve using the repetition of movements with the patient's arm actively involved in the performance. Various studies suggest that occupational therapy after stroke should be based on the repetition of movements [20].

Schöllhorn, who is considered one of the pioneers of differential teaching techniques, proposed differential training as educational theory opposing the movement repetition. The author states that the differential training approach has been developed according to the principles of individuality, movement system variability and the non-repeatability of movements on the basis of findings in neurophysiology and systems dynamics. Instead of just describing the fluctuations in the differential training, they are considered as intrinsic to the movement system and indispensable for adaptation. Fluctuations are understood as evidence for unstable regions of the system and instead of trying to eliminate them, it is more functional to enhance them in order to discover the space of possible performance solutions to prepare the athlete or patient for future events [7,8,21].

According to Frank et al., differential learning is a learning concept that helps a person to find the individual optimal models of performance taking into account the complex motor skills. To this end, learning takes place on a set time in a noisy environment, and it shows a great diversity of the different exercises. Experimental studies conducted by some authors, such as Frank et al., have shown that the performance improvement because of differential training is higher than that of traditional learning and differential learning helps improve the performance even after learning/training period [22].

So far, more research applying differential training has been carried out in various sports such as soccer [23], tennis [24], handball [25], volleyball [26], etc. It has been observed that with the application of differential training, athletes quickly learn techniques, develop motor skills, and learn new exercises and movements. One of the pioneers of this method provided a few examples of the research and the benefits of differential training: three soccer experiments with juvenile and adult skilled players within a pre- and posttest design and 8 interventions over 4 weeks resulted in significant higher acquisition rates than classical training methods [8,23]. During the intervention period, perturbations were added to the main technique by means of instruction. Instead of keeping the standing leg stiff, for example, the task was adapted for participants to kick with an extremely bent standing leg. The intervention period was characterized by no precise repetitions and no corrective instructions, but rather one new set of instructions after another. From a classical point of view, the movement executions looked like the training of erroneous movements. In a similar design with two additional retention tests after two and four weeks, students were taught the action of shot putting $[27,28]$. The results not only revealed significantly higher skill acquisition rates but also a further gain in performance during the following 4 weeks, while the classically trained group was able to improve its performance during the acquisition phase, but relaxed to the starting performance level within the first two subsequent weeks. Furthermore, the individual results displayed some improvements and some decrements in the classical group, whereas in the differential training group, only one athlete showed no change at all, while all others improved their performance at least to the same level as the best learners in the classical method group [8].

Schöllhorn et al. reported another important example: one group did nothing for 3 more weeks according to previous differential training experiments, the second group had to read training and biomechanical literature about the service technique in tennis, and the third group practiced mental training 3 times a week for $1 \mathrm{~h}$ in accordance with the programs $[8,24]$. The results showed an expected increase in precision for the classical differential training group. The literature group had a lightly smaller increase in performance, whereas the mental training group had a significant decrease in performance [8].

To the best of our knowledge, this is the first study that evaluated the effect of differential training on the recovery of arm function during rehabilitation, and our study showed differential training-based occupation therapy to be superior to the conventional one in terms of improved performance time of more functional tasks while performing the Wolf motor function test.

\section{Conclusions}

Both patients' groups improved arm function after occupational therapy sessions, but the patients who underwent conventional occupational therapy along with differential training-based occupational therapy recovered their arm function more effectively than their counterparts after conventional occupational therapy.

\section{Authors' contribution}

A.V. and D.B. conceived the original idea for the paper. V.R. wrote and designed the draft of the manuscript and was the lead investigator in this study. K.B. performed statistical analysis. All the authors (V.R., A.V., K.B., D.B., A.D., and E.S.) contributed to this study by making comments on the manuscript and were involved in the interpretation of findings. All the authors read and approved the final manuscript.

\section{Conflict of interest}

None declared. 


\section{Acknowledgement and financial support}

The authors declare no financial of interests.

\section{Ethics}

The study protocol was approved by Kaunas Regional Biomedical Research Ethics Committee (June 25, 2012, No. BE-2-28), and the State Data Protection Inspectorate gave permission to carry out personal data processing operations (August 24, 2012, No. 2R-3028 (2.6.1)).

\section{R E F E R E N C E S}

[1] Budrys V. Klinikinè neurologija [Clinical neurology].Vilnius. 2009.

[2] Petruševičienè D, Kriščiūnas A. Veiksniai, turintys įtakos sergančiujų galvos smegenų insultu ergoterapijos efektyvumui [Influence of factors on occupational therapy efficiency for patients after stroke]. Medicina (Kaunas) 2005;41(4):320-4.

[3] Higgins J, Salbach NM, Wood-Dauphinee S, Richards CL, Côté R, Mayo NE. The effect of a task-oriented intervention on arm function in people with stroke: a randomized controlled trial. Clin Rehabil 2006;20:296-310.

[4] Sethi A, Davis S, McGuirk T, Patterson TS, Richards LG. Effect of intense functional task training upon temporal structure of variability of upper extremity post stroke. J Hand Ther 2013;26(2):132-7. http://dx.doi.org/10.1016/j. jht.2012.09.001

[5] Kriščiūnas A, Kerpè R, Kimtys A, Mingaila S, Rapolienè J, Petruševičienè D, et al. Ergoterapija [Occupational therapy]. Kaunas: Vitae Litera; 2008.

[6] Petruševičienè D, Kriščiūnas A. Ligonių, sirgusių galvos smegenų insultu, ergoterapija [Occupational therapy for patients after stroke]. Medicina (Kaunas) 2003;11:1065-70.

[7] Schöllhorn WI, Beckmann H, Janssen DJ, Drepper J. Stochastic perturbations in athletics field events enhance skill acquisition. In: Renshaw I, Davids K, Savelsbergh GJP, editors. Motor learning in practice. A constraints-led approach. London: Routledge; 2010. p. 69-82.

[8] Schöllhorn WI, Beckmann H, Davids K. Exploiting systems fluctuations. Differential training in physical prevention and rehabilitation programs for health and exercise. Medicina (Kaunas) 2010;46(6):365-73.

[9] Beckmann H, Schöllhorn WI. Differential training in Soccer. In: Schöllhorn WI, Bohn C, Jäger JM, Schaper H, Alichmann M, editors. European Workshop on Movement Science. Köln: Sport und Buch Straub; 2003. p. 68.

[10] Wolf SL, Catlin PA, Ellis M, Archer AL, Morgan B, Piacentino A. Assessing Wolf Motor function test as outcome measure for research in patients with stroke. Stroke 2001;32(7): 1635-9. http://dx.doi.org/10.1161/01.STR.32.7.1635

[11] Wu H, Miyamoto Y, Gonzales-Castro LN, Olveczky BP, Smith MA. Temporal structure of motor variability is dynamically regulated and predicts motor learning ability.
Nat Neurosci 2014;17:312-21. http://dx.doi.org/10.1038/ $\underline{\mathrm{nn} .3616}$

[12] Herzfeld DJ, Shadmehr R. Motor variability is not noise, but grist for the learning mill. Nat Neurosci 2014;17(2):149-50.

[13] Skurvydas A. Judesių mokslas: raumenys, valdymas, mokymas, reabilitavimas, sveikatinimas, treniravimas, metodologija: vadovèlis. Kaunas: Lietuvos kūno kultūros akademija; 2008.

[14] Davids K, Bennet S, Newell K. Movement systems variability. Champaign, IL: Human Kinetic; 2006.

[15] Carr JH, Shepherd RB. Stroke rehabilitation. Guidelines for exercise and training to optimize motor skill; 2008.

[16] Lang CE, Bland MD, Bailey RR, Schaefer SY, Birkenmeier RL. Assessment of upper extremity impairment, function, and activity after stroke: foundations for clinical decision making. J Hand Ther 2013;26:104-15. http://dx.doi.org/ 10.1016/j.jht.2012.06.005

[17] Dobkin BH. Training and exercise to drive poststroke. Nat Clin Pract Neurol 2008;42(2):76-85. http://dx.doi.org/10.1038/ ncpneuro0709

[18] Dobkin BH. Rehabilitation after stroke. N Engl J Med 2005;352:1677-84. http://dx.doi.org/10.1056/NEJMcp043511

[19] Newell KM, Liu YT, Mayer-Kress G. Time scales in motor learning and development. Psychol Rev 2001;108(1):57-82. http://dx.doi.org/10.1037/0033-295X.108.1.57

[20] Feys H, De Weerdt W, Verbeke G, Steck GC, Capiau C, Kiekens C, et al. Early and repetitive stimulation of the arm can substantially improve the long-term outcome after stroke: a 5-year follow-up study of a randomized trial. Stroke 2004;35(4):924-9. http://dx.doi.org/10.1161/01. STR.0000121645.44752.f7

[21] Savelsbergh GJP, Kamper WJ, Rabius J, De Koning JJ, Schöllhorn WI. A new method to learn to start in speed skating: a differential learning approach. Int J Sport Psychol 2010;41:415-27.

[22] Frank TD, Michelbrink M, Beckmann H, Schöllhorn WI. A quantitative dynamical systems approach to differential learning: self-organization principle and order parameter equations. Biol Cybern 2008;98(1):19-31. http://dx.doi.org/ 10.1007/s00422-007-0193-x

[23] Schöllhorn WI, Michelbrink M, Beckmann H, Trockel M, Sechelmann M, Davids K. Does noise provide a basis for the unification of motor learning theories? Int J Sport Psychol 2006;37:34-42.

[24] Draksal M, Nittinger N. Mentales tennis-training [Menta] training in tennis]. Leipzig: Draksal-Fachverlag; 2002.

[25] Wagner H, Müller E. The effect of differential and variable training on the quality parameters of a handball throw. Sports Biomech 2008;7(1):54-71.

[26] Spratte M, Janssen D, Schöllhorn WI. Recognition of jumping patterns in volleyball after traditional and differential strength training by means of artificial neural nets. In: Beek P, van den Langenberg R, editors. 3rd European Workshop on Movement Sciences Book of Abstract, 167. 2007. p. 168 [abstract].

[27] Beckmann H, Schöllhorn WI. Differential learning in shot put [Differential learning in shot put]. Leistungs-sport 2006;36(4):44-50.

[28] Beckmann H, Schöllhorn WI. Differential learning in shot put. In: Schöllhorn WI, Bohn C, Jäger JM, Schaper H, Alichmann M, editors. 1st European Workshop on Movement Science. Köln: Sport \& Buch Strauß; 2003. p. 68. 